\title{
Greenhouses in the sky
}

\section{Emma Marris is intrigued by an optimistic vision of high-rise farms.}

$\mathrm{T}$ o feed the cities of the future, ecologist and microbiologist Dickson Despommier envisions a global shift to indoor agriculture. In The Vertical Farm, he sets out his big idea: by raising crops and animals in large urban buildings, former farmland can be returned to forest and rivers can be spared poisonous run-off. Cities will no longer have to transport food in and waste out, but will be self-sustaining - the urban equivalent of a natural ecosystem.

Despommier, who has developed and promoted his concept for a decade, imagines filling skyscrapers with hydroponically or aeroponically grown crops, medicinal herbs and biofuels fed on "ultrapure, chemically defined diets". Zones of plants would be dedicated to filtering the city's waste water back into drinkability. Every neighbourhood, rich or poor, would have access to wholesome, tasty, local food.

His idea is enthralling - but far from realized. It brings to mind the urban plans of King Camp Gillette, inventor of the safety razor, who sketched out a high-rise utopia in his 1894 book The Human Drift. His Metropolis was to be an enormous white porcelain city of "immaculate cleanliness", powered by Niagara Falls and run by machines, that would house the entire population of the United States. Gillette didn't bring agriculture within its walls - his vision was to import raw crops from surrounding lands and process them centrally. Despommier makes no mention of food processing in The Vertical Farm; perhaps in the future everyone cooks from scratch. He's clearly an optimist.

Like Gillette, Despommier has society's best interests at heart, but his proposal is grandiose. A professor of public health, he too is obsessed with cleanliness and offers discourses on the health threats of human faeces, rats and other vermin and the various contaminants that vertical-farm workers will

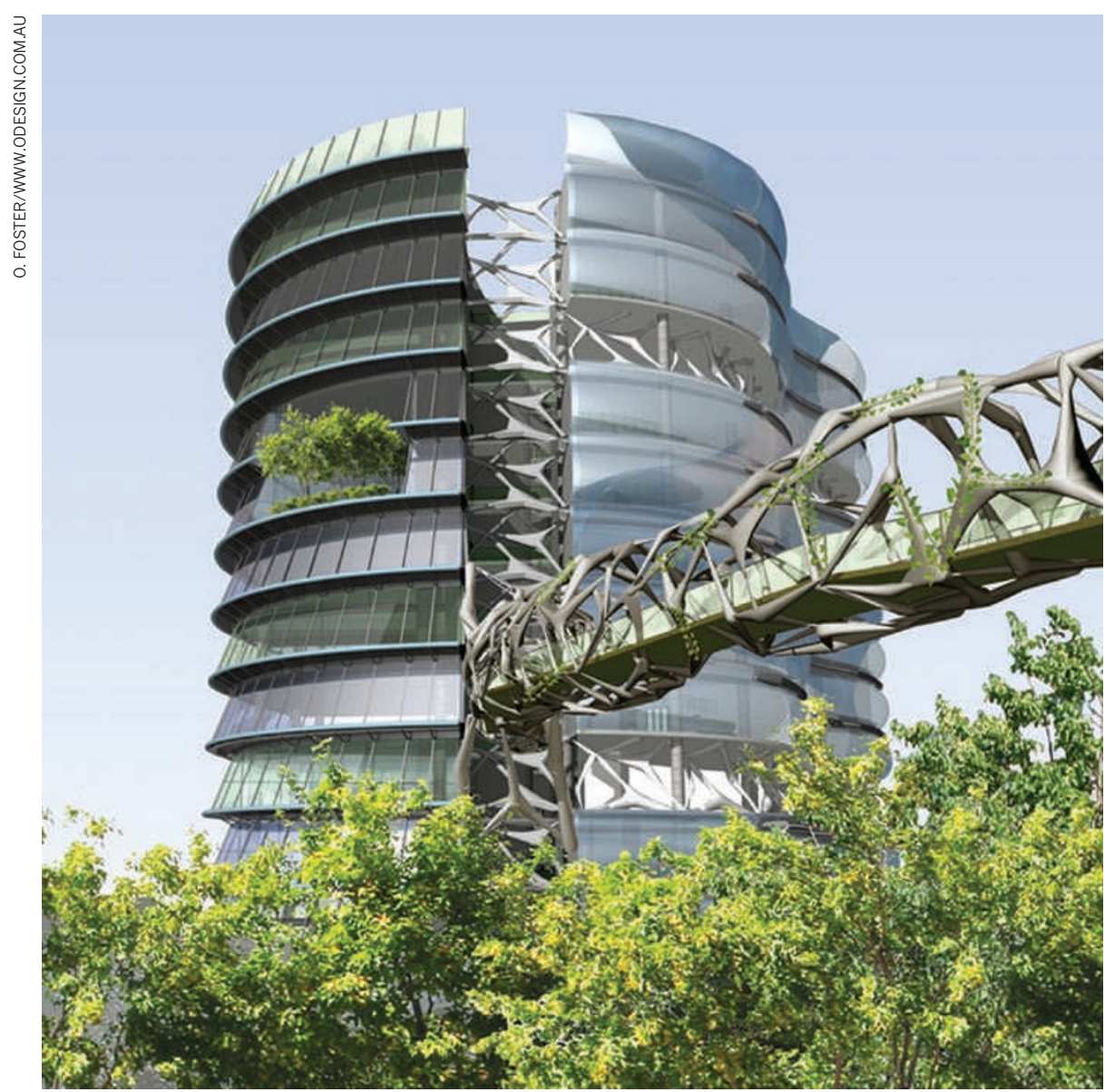

Bringing farms into city buildings might save on transport, but energy costs could skyrocket.

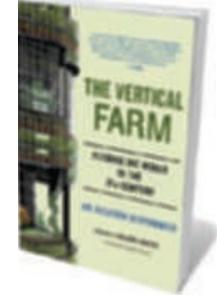

The Vertical Farm: Feeding the World in the 21st Century DICKSON DESPOMMIER

Thomas Dunne Books: 2010. 320 pp. $\$ 25.99$ \section{dence in hisidea. In ten} years of study, he tells us, he has thought of "no significant disadvantages" to his scheme, except the minor matters of construction costs and farmer displacement.

One downside is easy to spot: the massive amounts of energy required to grow plants indoors. Police often bust major marijuanagrowing operations by following up on unusually high electricity bills. Using coal or gas to grow strawberries and tomatoes is a lot more expensive than energy from the Sun. Despommier addresses this with transparent buildings and technology: light-emitting diodes on flexible plastics wrapped around individual plants, mirrors, solar panels, wind turbines and plasma-arc gasification facilities to turn biological waste into energy.

Yet his detail, he admits, doesn't extend to a quantitative demonstration that vertical farms are competitive in terms of either energy or money. He saves both by eliminating conventional farm machinery, pesticides, herbicides, fertilizer, transport and other costs, including crop failure. But he spends energy and money by building tall, complex buildings in urban cores and in acquiring and maintaining cutting-edge infrastructure, airtight security and negative-pressure ventilation.

Maybe growing all of our calories within the city limits is no more likely than thinking we'll all move to Metropolis. But The Vertical Farm is nevertheless inspiring. For some crops in some places, it might make sense. If Despommier won't do the maths, someone should. Any idea that might help us to avoid displacing any more natural areas with agriculture deserves a hearing. -

Emma Marris writes for Nature from Columbia, Missouri. 